\title{
Shale gas development impacts on surface water quality in Pennsylvania
}

\author{
Sheila M. Olmstead', Lucija A. Muehlenbachs, Jhih-Shyang Shih, Ziyan Chu, and Alan J. Krupnick \\ Resources for the Future, Washington, DC 20036
}

Edited by Maureen L. Cropper, University of Maryland, College Park, MD, and approved January 8, 2013 (received for review August 9, 2012)

\begin{abstract}
Concern has been raised in the scientific literature about the environmental implications of extracting natural gas from deep shale formations, and published studies suggest that shale gas development may affect local groundwater quality. The potential for surface water quality degradation has been discussed in prior work, although no empirical analysis of this issue has been published. The potential for large-scale surface water quality degradation has affected regulatory approaches to shale gas development in some US states, despite the dearth of evidence. This paper conducts a large-scale examination of the extent to which shale gas development activities affect surface water quality. Focusing on the Marcellus Shale in Pennsylvania, we estimate the effect of shale gas wells and the release of treated shale gas waste by permitted treatment facilities on observed downstream concentrations of chloride $\left(\mathrm{Cl}^{-}\right)$ and total suspended solids (TSS), controlling for other factors. Results suggest that (i) the treatment of shale gas waste by treatment plants in a watershed raises downstream $\mathrm{Cl}^{-}$concentrations but not TSS concentrations, and (ii) the presence of shale gas wells in a watershed raises downstream TSS concentrations but not $\mathrm{Cl}^{-}$concentrations. These results can inform future voluntary measures taken by shale gas operators and policy approaches taken by regulators to protect surface water quality as the scale of this economically important activity increases.
\end{abstract}

unconventional gas | water pollution | econometric analysis | panel data

$\mathbf{W}$ ith the advance of hydraulic fracturing technology and improvements in horizontal well drilling, the development of natural gas supplies from deep shale formations has expanded and US natural gas supply estimates have risen dramatically (1). These resources have significant economic value and could generate local air quality benefits if gas displaces coal in electricity generation and for climate change if fugitive methane emissions are sufficiently small (2). Nonetheless, shale gas development has drawn significant public and regulatory attention to potential negative environmental externalities, particularly water quality impacts in the Marcellus Shale region $(3,4)$.

Groundwater impacts of shale gas development have been considered in the literature. Methane may migrate from shale gas wells into drinking water wells in Pennsylvania and New York (5). Shale formation brine may also naturally migrate to groundwater aquifers in Pennsylvania, although this result is debated in the literature (6) and no association has been found with the location of shale gas wells (7). Case studies of isolated incidents of groundwater contamination also suggest links with shale gas activity (8).

The potential risk to New York City's surface water supply from the Delaware River Basin was a primary driver behind a 2011 ban on hydraulic fracturing in New York State. In contrast to the case of groundwater, however, empirical estimates of the effects of shale gas development on surface water quality are not available, although the issue has been raised in the recent literature $(9,10)$.

We conduct a large-scale statistical examination of the extent to which shale gas development affects surface water quality. Focusing on the Marcellus Shale, a major US shale play, we construct a Geographic Information Systems (GIS) database from several publicly available sources, including 20,283 water quality observations in Pennsylvania (2000-2011), shale gas well locations, shipments of shale gas waste to treatment facilities, and water body characteristics. We exploit temporal and spatial variation in the location of wells and waste treatment facilities relative to water quality monitors to identify impacts on downstream water quality. Using regression analysis, we find measurable impacts of upstream shale gas activity on downstream water quality. Increasing the upstream density of wastewater treatment plants that release treated shale gas waste to surface water by $1 \mathrm{SD}$ increases downstream chloride $\left(\mathrm{Cl}^{-}\right)$concentrations by $10-11 \%$. A 1-SD increase in the density of well pads upstream increases total suspended solid (TSS) concentrations downstream by $5 \%$. In contrast, we find no statistically significant impact of wells on downstream $\mathrm{Cl}^{-}$concentrations or of waste treatment on downstream TSS concentrations. These findings are consistent with concerns raised for surface water quality in the literature: Shale gas wastewater is typically high in $\mathrm{Cl}^{-}$ (among other dissolved solids), making it difficult to treat, and the construction of well pads, pipelines, and roads can increase sediment runoff and TSS $(9,10)$.

The econometric approach used here cannot identify or rule out individual instances of water quality contamination. The analysis models average impacts at coarse temporal and spatial scales as a function of shale gas development, controlling for other factors. Thus, it is a complement to physical science studies that would make precise connections between water quality changes at a fine temporal and spatial scale and specific shale gas activities.

\section{Shale Gas Activity and Water Quality Indicators}

Indicators of water quality impacts from shale gas development must meet three criteria for the analysis: They are associated with shale gas development, they are observed at a large number of water quality monitors and with enough spatial and temporal variation relative to shale gas activity to support statistical analysis, and they have the potential to cause water quality damage. Concentrations of $\mathrm{Cl}^{-}$and TSS meet these criteria.

Brine from conventional oil and gas operations has been associated with increased stream $\mathrm{Cl}^{-}$levels in other regions $(11,12)$. Shale gas development generates large quantities of flowback and produced water high in $\mathrm{Cl}^{-}$(9). The peak in fluid storage and transport occurs during well fracturing and completion, when 2-4 million gallons of freshwater and fracturing fluids transported by truck or (for freshwater) pipeline are pumped into a well (13). From $10-70 \%$ of this volume may return as flowback, along with formation brine and naturally occurring contaminants, such as heavy metals and radionuclides. Direct discharge of fluids from well sites is illegal. Fluids are collected at well pads and transported onand off-site for reuse, recycling, treatment, and disposal. Media

Author contributions: S.M.O. and A.J.K. designed research; S.M.O. and L.A.M. performed research; S.M.O., L.A.M., J.-S.S., and Z.C. analyzed data; and S.M.O., L.A.M., and A.J.K. wrote the paper.

The authors declare no conflict of interest.

This article is a PNAS Direct Submission.

Freely available online through the PNAS open access option.

${ }^{1}$ To whom correspondence should be addressed. E-mail: olmstead@rff.org

This article contains supporting information online at www.pnas.org/lookup/suppl/doi:10 1073/pnas.1213871110/-/DCSupplemental. 
coverage of Marcellus Shale development suggests potential risks of leakage from storage pits and impoundments, spills, and other accidental releases $(3,14)$.

A large and increasing fraction of shale gas wastewater in Pennsylvania is recycled for use in other well completions. Some waste is shipped to deep injection wells in Ohio and other neighboring states. (Most of Pennsylvania is geologically unsuitable for deep injection wells. Seismic concerns have arisen regarding injection of large quantities of shale gas waste into these wells $(15,16)$.) Operators have also shipped shale gas waste to municipal and industrial wastewater treatment facilities, although the effectiveness of treatment processes in these facilities for removing contaminants in shale gas waste is poorly understood, and salts (including $\mathrm{Cl}^{-}$) are of particular concern (17). (Shipments to municipal facilities stopped as of January 2012; those to industrial facilities continue.) Average total dissolved solid (TDS) concentrations in shale gas waste range from 800 to $300,000 \mathrm{mg} / \mathrm{L}$, typical ocean water concentration is 35,000 $\mathrm{mg} / \mathrm{L}$, and freshwater concentration is $100-500 \mathrm{mg} / \mathrm{L}(18)$. Concern over the limited capacity of Pennsylvania rivers and streams to assimilate TDSs that remain in wastewater treatment plant effluent considering existing sources, such as coal mine drainage and conventional wastewater effluent, prompted the introduction of new state wastewater treatment standards for TDSs in 2011. [In 2008, monitors detected record TDS levels (mainly $\mathrm{Cl}^{-}$and sulfates) in sections of the Monongahela River during low late summer-early fall flows, and 13 public drinking water system intakes in Pennsylvania and West Virginia exceeded secondary maximum contaminant levels under the Safe Drinking Water Act, persisting through December 2008 (18).]

Elevated or fluctuating $\mathrm{Cl}^{-}$concentrations can directly damage aquatic ecosystems (19). $\mathrm{Cl}^{-}$may also mobilize heavy metals, phosphates, and other chemicals present in sediment (20). Treatment of waste high in $\mathrm{Cl}^{-}$is expensive because the $\mathrm{Cl}^{-}$is not easily removed by chemical or biological processes once it is in solution (21); thus, high $\mathrm{Cl}^{-}$concentrations may also increase costs for downstream water users (e.g., industrial or drinking water facilities).

Land clearing and construction can increase TSS in local water bodies, particularly when precipitation accelerates sediment transport, increases flow rates so that water carries more and larger sediments, and resuspends sediments. Pad construction, changes to local roadways, pipeline construction, and other shale gas development activities could contribute to this problem (9). Gas well sites in Texas have been shown to produce sediment loads comparable to traditional construction sites (22). However, the US Energy Policy Act of 2005 generally exempts oil and gas construction sites from Clean Water Act (CWA) stormwater regulations. In Pennsylvania, non-oil-and-gas construction sites larger than 1 acre must install erosion and sediment control infrastructure; shale gas sites larger than 5 acres must file erosion and sediment control plans. Most shale gas well sites are not large enough to trigger this review, although many Marcellus Shale operators do install stormwater control infrastructure (13). In addition to impacts from infrastructure, TSS concentrations could be increased by shale gas waste treatment, although most wastewater treatment plants are designed to remove suspended solids (13).

TSS (silt, decaying organic matter, industrial wastes, and sewage that can be trapped by a fine filter) in surface water reduce available sunlight, raise temperature, decrease dissolved oxygen and clarity, and ultimately damage biological condition (23). Solids can also clog or scour pipes and machinery for downstream water users, increasing costs.

\section{Data}

Our GIS database combines several sources of data (additional details are provided in SI Data). The Storage and Retrieval Data
Warehouse (STORET) database of the Environmental Protection Agency (EPA) provided 8,364 $\mathrm{Cl}^{-}$concentration observations from 860 Pennsylvania water quality monitors between January 2000 and December 2011 (with $98 \mathrm{~d}$, on average, between readings at a monitor). TSS concentrations from the STORET database for the same time period comprise 11,919 observations from 644 monitors (with readings every $55 \mathrm{~d}$, on average).

The independent variables of greatest interest capture the density of shale gas wells in a monitor's watershed and the scale of shale gas waste treatment and release in a monitor's watershed. The latitude and longitude and the drilling and completion dates of 4,908 shale gas wells drilled through December 2011 were obtained from the Pennsylvania Department of Environmental Protection (PADEP) and the Pennsylvania Department of Conservation and Natural Resources (PADCNR). The PADEP also provided the destination and quantity of wastewater shipments from wells to 74 permitted treatment facilities that accepted shale gas waste at some point between 2004 (the year of the first observed shipment) and 2011. In 2004, 0.003 million barrels (MMbbl) of liquid shale gas waste were shipped to 3 treatment facilities; in 2011, about 17.7 MMbbl were shipped to 50 facilities. We obtained the latitude and longitude of these facilities, as well as others permitted under the CWA's National Pollutant Discharge Elimination System (NPDES), from the EPA. Daily precipitation data were downloaded from the National Oceanic and Atmospheric Administration's National Climatic Data Center.

We generated well counts, shale gas waste treatment facility counts, and waste shipment amounts in the upstream portion of each monitor's watershed. Thus, we focus only on within-watershed impacts, excluding any potential impacts further downstream. (Estimating impacts in downstream watersheds would require hydrological modeling of the attenuation over time and space of contaminant concentrations, which is beyond the scope of this study. However, the most significant impacts, if any, should be detectable within watersheds.) Watershed boundaries were determined using a US Geological Survey digital elevation model, HYDRO1k. Flow direction and accumulation were determined using a $1-\mathrm{km}$ by $1-\mathrm{km}$ grid size in HYDRO1k in ArcGIS. A flow accumulation threshold of $1,000 \mathrm{~km}^{2}$ was used to delineate 79 Pennsylvania watersheds, averaging $1,502 \mathrm{~km}^{2}$.

\section{Research Design}

The research design exploits spatial variation in the location of water quality monitors, shale gas wells, and NPDES-permitted waste treatment facilities that have accepted shale gas waste (Fig. 1), along with intertemporal variation generated by the timing of well development and waste shipments. The effects of interest are estimated using regression analysis (Supporting Information).

We test for the impact of shale gas development on surface water $\mathrm{Cl}^{-}$concentrations via two potential pathways. First, to consider the possibility of accidental releases from well sites, we analyze the impact on $\mathrm{Cl}^{-}$concentrations of the density of shale gas wells upstream in a water quality monitor's watershed (the count of upstream wells on the date a sample was drawn, divided by the area of the upstream portion of the watershed). The statistical models (Eq. S1) also test whether any estimated impacts of wells on downstream $\mathrm{Cl}^{-}$are more significant during well fracturing and completion. Second, the models examine the impact of waste fluid shipments on downstream $\mathrm{Cl}^{-}$concentrations, considering both the density of treatment facilities accepting shale gas waste (the count of upstream facilities accepting waste during the period in which the sample is drawn, divided by upstream area) and the quantity of shipments reported to the PADEP upstream in a water quality monitor's watershed. We also test for differences in the impacts of upstream treatment of shale gas waste by different types of treatment facilities. Facilities accepting Pennsylvania shale gas waste between 2004 and 2011 include municipal sewage treatment plants, or 


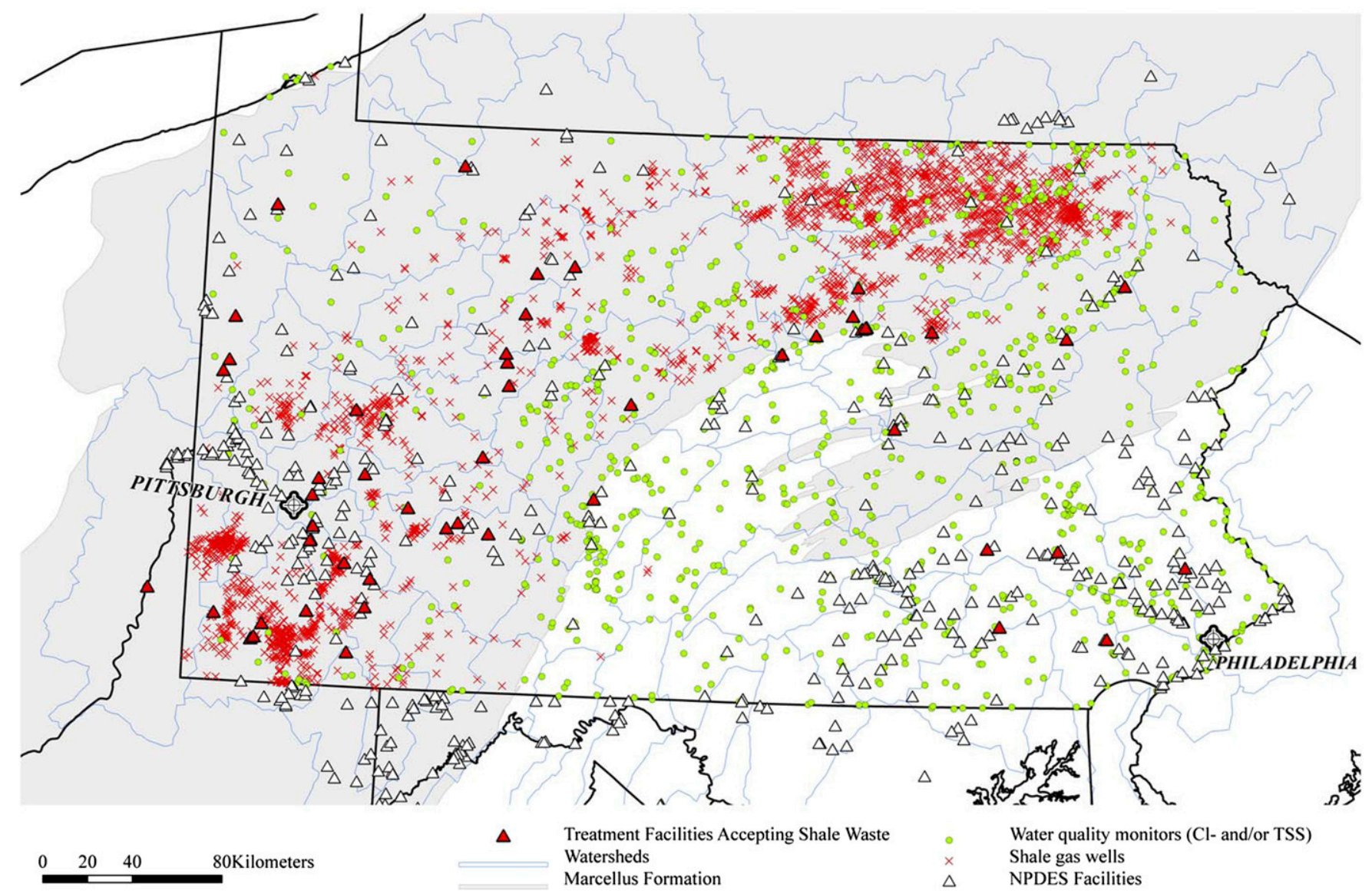

Fig. 1. Surface water quality monitors, shale gas wells, and wastewater treatment facilities in Pennsylvania watersheds (2000-2011).

publicly owned treatment works (POTWs), and industrial centralized waste treatment (CWT) facilities. Facilities' NPDES permits determine their eligibility to treat shale gas waste, and regulation of these flows changed during the period of observation. Regulatory changes in January 2011 increased the stringency of treatment requirements, although a specific group of grandfathered POTWs and CWTs was initially exempt from new requirements and then subject to a voluntary ban on waste shipments from operators in May 2011 (Supporting Information). The statistical models test for differential effects on downstream $\mathrm{Cl}^{-}$concentrations of shale gas waste treatment at facilities affected by these regulatory changes and those that were not.

We analyze the impacts of shale gas development on surface water TSS concentrations via the same two basic pathways considered for $\mathrm{Cl}^{-}$: impacts from wells and impacts from waste disposal at permitted treatment facilities. However, rather than examining more closely the period during well completion, as we did for $\mathrm{Cl}^{-}$, the TSS models consider whether any estimated impacts of wells on TSS are concentrated between the permit date and spud date (the date on which well drilling begins), when land clearing and pad construction would take place.

To identify the impacts of shale gas wells and waste treatment on $\mathrm{Cl}^{-}$and TSS concentrations, we must adequately control for other contributing factors. All models include controls for precipitation, summing daily precipitation in a monitor's watershed on the day of a monitor observation plus cumulative precipitation on the $3 \mathrm{~d}$ before each observation. The models control for other potential influences on $\mathrm{Cl}^{-}$and TSS concentrations using a standard econometric approach, including groups of fixed effects (FEs) as controls. We control for average concentrations at each monitor over time with monitor FEs. Year-month FEs (132 for the months January 2000-December 2011) control for all time-varying characteristics of Pennsylvania water quality, generally, that are correlated over space (e.g., trends in economic activity, such as those related to the recent recession). Watershed-calendarmonth (January-December) FEs control for seasonal changes in contaminant concentrations that may be specific to a watershed.

Together, the FEs narrow the sources of spatial and intertemporal variation in contaminant concentrations from which the effects of interest are identified, so as to exclude potential confounders. For example, an important source of $\mathrm{Cl}^{-}$in Pennsylvania rivers and streams is road salt. The monitor FEs control for the fact that some monitors consistently receive more road salt from upstream sources than others. The year-month FEs control for the fact that for all Pennsylvania monitors, some months between January 2000 and December 2011 witness higher $\mathrm{Cl}^{-}$concentration from road salt than others, and the watershed-calendar-month FEs control for the fact that some months of the year are typically subject to higher concentrations of $\mathrm{Cl}^{-}$from road salt than others, and the magnitude of this interannual variation varies by watershed. Further analysis decomposing some of these FEs, to demonstrate that the models control sufficiently for important potential confounders, is provided in Supporting Information.

\section{Results}

Estimated Impacts on $\mathrm{Cl}^{-}$Concentrations. A FE regression of observed $\mathrm{Cl}^{-}$concentration on the FEs and precipitation shows that an increase in precipitation reduces $\mathrm{Cl}^{-}$concentration. The magnitude of this simple dilution result does not change across specifications (Table 1). 
Table 1. Estimated impacts of shale gas wells and waste treatment on downstream $\mathrm{Cl}^{-}$concentrations (milligrams per liter)

\begin{tabular}{|c|c|c|c|c|c|c|}
\hline Variable & (1) & (2) & (3) & (4) & (5) & (6) \\
\hline Cumulative precipitation $(4 \mathrm{~d}), \mathrm{mm}$ & $\begin{array}{l}-0.003 * * * \\
(0.001)\end{array}$ & $\begin{array}{l}-0.003 * * * \\
(0.001)\end{array}$ & $\begin{array}{l}-0.003 * * * \\
(0.001)\end{array}$ & $\begin{array}{l}-0.003 * * * \\
(0.001)\end{array}$ & $\begin{array}{l}-0.003 * * * \\
(0.001)\end{array}$ & $\begin{array}{l}-0.003 * * * \\
(0.001)\end{array}$ \\
\hline Gas wells upstream $/ \mathrm{km}^{2}$ & & $\begin{array}{c}17.076 \\
(16.219)\end{array}$ & & $\begin{array}{c}10.312 \\
(16.952)\end{array}$ & & $\begin{array}{c}20.204 \\
(19.245)\end{array}$ \\
\hline Gas wells upstream $(0-90 \mathrm{~d}) / \mathrm{km}^{2}$ & & & $\begin{array}{c}55.196 \\
(126.292)\end{array}$ & & & \\
\hline Gas wells upstream $(90-180 \mathrm{~d}) / \mathrm{km}^{2}$ & & & $\begin{array}{c}-36.500 \\
(93.82)\end{array}$ & & & \\
\hline Facilities accepting waste upstream $/ \mathrm{km}^{2}$ & & $\begin{array}{c}2,223.660 * * * \\
(681.868)\end{array}$ & $\begin{array}{c}2,240.228^{* * *} \\
(696.602)\end{array}$ & $\begin{array}{c}2,116.823^{* * *} \\
(696.135)\end{array}$ & $\begin{array}{c}2,086.356 * * * \\
(683.888)\end{array}$ & \\
\hline Waste quantity treated upstream, $\mathrm{MMbbl} / \mathrm{km}^{2}$ & & & & $\begin{array}{c}152.873 \\
(140.226)\end{array}$ & $\begin{array}{c}205.601 * \\
(119.618)\end{array}$ & \\
\hline Nonaffected facilities accepting waste $/ \mathrm{km}^{2}$ & & & & & & $\begin{array}{c}2,625.909 \\
(4,164.453)\end{array}$ \\
\hline Affected facilities accepting waste $/ \mathrm{km}^{2}$ & & & & & & $\begin{array}{c}1,927.716^{* *} \\
(902.173)\end{array}$ \\
\hline$N$ & 8,402 & 8,364 & 8,364 & 8,364 & 8,364 & 8,364 \\
\hline Mean $\mathrm{Cl}^{-}, \mathrm{mg} / \mathrm{L}$ & 19.077 & 19.074 & 19.074 & 19.074 & 19.074 & 19.074 \\
\hline$R^{2}$ & 0.499 & 0.499 & 0.499 & 0.499 & 0.499 & 0.499 \\
\hline
\end{tabular}

Sample includes all monitor measurements of $\mathrm{Cl}^{-}$(milligrams per liter), 2000-2011. Variables divided by square kilometers are divided by the area of the watershed that is upstream of the monitor. All regressions include FEs for year-month, watershed-calendar month, and monitor. Reported SEs are robust and clustered by watershed. Statistically significant at the $* 10 \%$ level; $* \star 5 \%$ level; $* * \star 1 \%$ level.

The density of shale gas wells upstream in a monitor's watershed has a statistically insignificant effect on $\mathrm{Cl}^{-}$concentration downstream, although coefficient estimates are positive (Table 1, columns 2, 4, and 6). Limiting the well density variable to only those wells spudded within 0-90 d and within 90-180 d before a $\mathrm{Cl}^{-}$sample is drawn at a downstream water quality monitor should capture the greatest potential for accidental releases affecting surface water, because reported completion dates in our dataset are, on average, $80 \mathrm{~d}$ after a well's spud date (SI Data). (We cannot construct variables centered on a known completion date, because firms report completion dates to the PADEP and/ or PADCNR for only 1,815 of the 4,908 wells drilled through December 2011. A nonreported completion date does not necessarily indicate that a well has not been completed; 877 wells without a completion date report production before the end of 2011.) Nonetheless, we find no statistically significant impact of wells at this development stage on observed $\mathrm{Cl}^{-}$concentrations (Table 1, column 3).

In contrast, the density of waste treatment facilities accepting shale gas waste upstream in a monitor's watershed increases $\mathrm{Cl}^{-}$ concentrations at monitors downstream (Table 1, columns 2-5). The annual quantity of wastewater shipped to waste treatment facilities upstream of a monitor, divided by the upstream area of the watershed, has varying statistical significance (Table 1, columns 4-5). Waste shipment quantity data are potentially problematic (SI Data). However, they represent the only data currently available on the quantity of shale gas waste treated and released by particular facilities. The quantity of waste shipped to treatment facilities in a watershed is correlated with the density of shale gas wells. If the density of wells is included in the analysis, the waste quantity is positive but statistically insignificant (Table 1, column 4). If the wells variable is dropped, the waste quantity variable is positive and weakly significant (Table 1, column 5). Because the coefficients of the wells are statistically insignificant in all models, this suggests a potential marginal effect of the quantity of waste treated and released upstream on $\mathrm{Cl}^{-}$concentrations, controlling for the spatial density of treating facilities.

The impact of treated shale gas waste on downstream $\mathrm{Cl}^{-}$ concentrations may vary across treatment facilities. We divide facilities into those that were affected by the 2011 voluntary request to suspend shipments (POTWs and grandfathered CWTs) and those that were not affected (nongrandfathered CWTs). Results suggest that the observed increase in downstream $\mathrm{Cl}^{-}$ concentrations is due more to the facilities that have received regulatory attention than to those that have not; the coefficient on the affected facilities is positive and statistically significant (Table 1, column 6). However, the PADEP data indicate that some affected facilities accepted shale gas waste during the period July 2011-December 2011, although operators were to have voluntarily stopped sending waste to these facilities in May 2011 (Supporting Information).

Estimated Impacts on TSS Concentrations. A simple model regressing observed TSS concentrations on the FEs and precipitation finds that precipitation in the watershed increases TSS concentrations (Table 2). The magnitude of this expected effect does not change as we alter model specification.

The density of upstream waste treatment facilities accepting shale gas waste has a statistically insignificant effect on downstream TSS concentrations, although the coefficients are positive (Table 2, columns 2-5). The density of shale gas wells upstream in a monitor's watershed, in contrast, has a positive and significant impact on downstream TSS concentrations (Table 2, column 2).

We also test for the relative impact of well pad preparation vs. activities specific to individual wells. The data do not indicate which wells are on the same well pad; thus, we assume that wells within 1 acre share a pad. The average number of wells on a pad using this method is about 3.7.* We then create a variable describing the density of well pads upstream in a monitor's watershed. If pad preparation is a more significant driver of TSS impacts than individual wells, the magnitude of the well pad estimate should be less than the impact of an individual well,

\footnotetext{
*During completion, a multiwell pad, access road, and infrastructure are estimated to cover 7.4 acres; after completion and partial reclamation, a multiwell pad averages 4.5 acres (24). Using our estimates, of the wells that are within $63 \mathrm{~m}$ (1 acre), $50 \%$ are within $11 \mathrm{~m}$ and $75 \%$ are within $20 \mathrm{~m}$. The average number of wells per well pad is 3.7 (with a maximum of 12), and $25 \%$ of our well pad groups have only one well. Many wells in our data are on pads for which some wells have yet to be drilled, and 1 acre may be a conservative estimate of well proximity on a pad; thus, 3.7 is lower than the average number of wells per completed pad in Pennsylvania.
} 
Table 2. Estimated impacts of shale gas wells and waste treatment on downstream TSS concentrations (milligrams per liter)

\begin{tabular}{|c|c|c|c|c|c|}
\hline Variable & (1) & (2) & (3) & (4) & (5) \\
\hline \multirow[t]{2}{*}{ Cumulative precipitation ( $4 \mathrm{~d}), \mathrm{mm}$} & $0.086^{*}$ & $0.086 * * *$ & $0.086 * * *$ & $0.085^{* * *}$ & $0.086 * * *$ \\
\hline & $(0.025)$ & $(0.025)$ & $(0.025)$ & $(0.026)$ & $(0.025)$ \\
\hline \multirow[t]{2}{*}{ Facilities accepting waste upstream $/ \mathrm{km}^{2}$} & & 706.063 & 692.274 & 691.812 & 695.183 \\
\hline & & $(454.138)$ & $(456.297)$ & $(461.978)$ & $(451.551)$ \\
\hline \multirow[t]{2}{*}{ Gas wells upstream $/ \mathrm{km}^{2}$} & & $45.965^{* *}$ & & & \\
\hline & & $(22.867)$ & & & \\
\hline \multirow[t]{2}{*}{ Well pads upstream $/ \mathrm{km}^{2}$} & & & $97.072 *$ & 3.427 & 100.921 \\
\hline & & & $(54.548)$ & $(127.972)$ & (71.640) \\
\hline \multirow[t]{2}{*}{ Well pads upstream $/ \mathrm{km}^{2} \times(4-\mathrm{d}$ precipitation $)$} & & & & 0.514 & \\
\hline & & & & $(0.867)$ & \\
\hline \multirow{2}{*}{ Well pads permitted, prespud upstream $/ \mathrm{km}^{2}$} & & & & & -102.865 \\
\hline & & & & & $(892.745)$ \\
\hline$N$ & 11,919 & 11,919 & 11,919 & 11,919 & 11,919 \\
\hline Mean TSS, mg/L & 20.392 & 20.392 & 20.392 & 20.392 & 20.392 \\
\hline$R^{2}$ & 0.283 & 0.283 & 0.283 & 0.283 & 0.283 \\
\hline
\end{tabular}

multiplied by the average number of wells on a pad. The well pad variable is positive, weakly significant (Table 2, column 3 ), and about twice the magnitude of the variable for individual wells (Table 2, column 2). Although we may have introduced some attenuation bias from measurement error in constructing the well pad variable, this result is consistent with the hypothesis that the net TSS impacts of wells may be due more to well pad preparation than to activities associated with individual wellbores.

If the TSS impacts we estimate from shale gas wells are due to stormwater-related transport of sediment to water bodies, they should intensify with rain. Interacting the well pad density variable with precipitation does not support this hypothesis; coefficients on well pad density and the interaction term are positive but statistically insignificant (Table 2, column 4). Finally, if these impacts are related primarily to disturbance from land clearing and pad construction, we should observe stronger impacts from pads on which the first observed well is between the permit date and the spud date than from pads that are further along in development. However, permitted but undrilled wells are negative and insignificant, and the statistical significance of the well pads variable disappears as well (Table 2, column 5). (The coefficient estimate on the density of well pads for which one or more wells are permitted but not yet spudded remains insignificant if we drop the variable capturing the total number of well pads.)

\section{Interpretation and Discussion}

Results for $\mathrm{Cl}^{-}$suggest that the presence of shale gas wells upstream in a monitor's watershed does not raise observed concentrations but that the treatment and release of wastewater from shale gas wells by permitted facilities upstream in a monitor's watershed does. These results are not consistent with the presence of significant flows of high- $\mathrm{Cl}^{-}$shale gas waste through accidental releases directly into surface water from well sites. However, surface water disposal of treated waste from shale gas wells represents a potentially important water quality burden. Taking into account average watershed size and mean $\mathrm{Cl}^{-}$concentrations, the coefficients in Table 1 suggest that a 1-SD increase in the spatial density of upstream waste treatment facilities (an additional 1.5 facilities treating waste upstream in a watershed) results in a $10-11 \%$ increase in $\mathrm{Cl}^{-}$downstream, depending on the specification. (We calculate this effect as follows: (SD of upstream facilities per $\mathrm{km}^{2} \times$ coefficient)/average $\mathrm{Cl}^{-}$concentration.)
Shale gas wastewater shipments to Pennsylvania POTWs have ceased as of January 2012. However, the documentation of a measurable surface water impact from only the first years of burgeoning development is relevant to CWTs that continue to treat shale gas wastewater as well as to other jurisdictions considering treatment by POTWs. Furthermore, apart from $\mathrm{Cl}^{-}$, many other wastewater constituents could potentially reach surface water, although available data on their concentrations is limited (Supporting Information).

Results for TSS suggest a different pathway of potential concern. The presence of shale gas wells upstream in a monitor's watershed raises observed TSS concentrations downstream. Increasing the average density of well pads upstream in a monitor's watershed by $1 \mathrm{SD}$ (an additional 18 well pads) results in about a $5 \%$ increase in observed TSS concentrations (Table 2, column $3)$. Shale gas waste shipments to permitted treatment facilities do not appear to raise TSS concentrations. In the case of TSS, the primary water quality burden may be associated with the process of clearing land for infrastructure. However, given that we do not detect an increase in TSS impacts of well pads during precipitation events, or an increase associated with well pads in construction, the particular mechanisms through which shale gas infrastructure may increase TSS in local water bodies are unclear. Further analysis using data on pipeline and new road construction would be helpful in this regard. The observed increase in TSS concentrations could potentially be associated with spills or other emissions at well sites, rather than construction, but the inability of our models to detect increases in $\mathrm{Cl}^{-}$from well sites (a strong marker for shale gas waste, relative to TSS, which have many more sources) is not consistent with this possibility.

The nature of surface water contamination from shale gas development considered here is qualitatively different from the groundwater concerns explored in the literature $(5,7)$. Although groundwater concerns may have primarily to do with contamination directly from wellbores or shale formations, surface water concerns may have primarily to do with off-site waste treatment and aboveground land management.

The effects of shale gas development on surface water quality that we estimate control for average contaminant concentrations at a monitor, average concentrations for each month in the data, and average concentrations in each calendar month by watershed, as well as precipitation. Thus, the shale gas coefficient 
estimates are identified from within-monitor variation in contaminant concentrations, controlling carefully for exogenous trends in water quality. However, this approach cannot confirm or rule out individual accidental releases of flowback and other fluids to surface water. Our approach is complementary to physical science studies that would establish the exact mechanisms through which shale gas development may affect downstream surface water quality.

Finally, the economically optimal level of pollution is generally not zero, and further work would be necessary to quantify the benefits and costs of the shale gas development activities gen-

1. US Energy Information Administration (2012) Annual Energy Outlook 2012, DOE/EIA 0383(2012) (US Energy Information Administration, Washington, DC).

2. Alvarez RA, Pacala SW, Winebrake JJ, Chameides WL, Hamburg SP (2012) Greater focus needed on methane leakage from natural gas infrastructure. Proc Natl Acad Sci USA 109(17):6435-6440

3. Urbina I (February 23-December 31, 2011) Drilling down series. The New York Times. Available at http://www.nytimes.com/interactive/us/DRILLING_DOWN_SERIES html. Accessed February 21, 2013

4. US Environmental Protection Agency, Office of Research and Development. (2011) Plan to Study the Potential Impacts of Hydraulic Fracturing on Drinking Water Resources EPA/600/R-11/122 (US Environmental Protection Agency, Washington, DC).

5. Osborn SG, Vengosh A, Warner NR, Jackson RB (2011) Methane contamination of drinking water accompanying gas-well drilling and hydraulic fracturing. Proc Nat Acad Sci USA 108(20):8172-8176.

6. Saiers JE, Barth E (2012) Potential contaminant pathways from hydraulically fractured shale aquifers. Ground Water 50(6):826-828, discussion 828-830.

7. Warner NR, et al. (2012) Geochemical evidence for possible natural migration of Marcellus Formation brine to shallow aquifers in Pennsylvania. Proc Natl Acad Sci USA 109(30):11961-11966.

8. US Environmental Protection Agency, Office of Research and Development, Nationa Risk Management Research Laboratory. (2011) Investigation of Ground Water Contamination near Pavillion, Wyoming, EPA 600/R-00/000 (US Environmental Protection Agency, Ada, OK).

9. Entrekin S, Evans-White M, Johnson B, Hagenbuch E (2011) Rapid expansion of natural gas development poses a threat to surface waters. Front Ecol Environ 9(9): 503-511.

10. Rozell D, Reaven S (2012) Water pollution risk associated with natural gas extraction from the Marcellus Shale. Risk Anal 32(8):1382-1393, 10.1111/j.1539 6924.2011.01757.x

11. Nance $H$ (2006) Tracking salinity sources to Texas streams: Examples from West Texas and the Texas Gulf Coastal Plain. Gulf Coast Assoc Geol Soc Trans 56:675-693.

12. Shipley $F(1991)$ Oil field-produced brines in a coastal stream: Water quality and fish community recovery following long term impacts. Tex I Sci 43(1):51-64.

13. Veil J (2010) Water Management Technologies Used by Marcellus Shale Gas Producers, Final Report, DOE Award No. FWP 49462 (US Department of Energy, Argonne National Laboratory, Argonne, IL). erating these externalities, including monetization of our estimated $\mathrm{Cl}^{-}$and TSS impacts. The results highlight the need for further research on the surface water quality impacts of shale gas development, and they may provide input to operator decisions and regulatory processes regarding well location, waste disposal, erosion control, and contaminant monitoring.

ACKNOWLEDGMENTS. We thank Will Wheeler at the US EPA for data on NPDES-permitted facilities in Pennsylvania and New York, the Bureau of Topographic and Geologic Survey of the PADCNR for data on well completions, and Stefan Staubli. We gratefully acknowledge financial support from the Alfred P. Sloan Foundation.

4. Slater D (2011) Watershed moment. Sierra 96(5):14

15. Ohio Department of Natural Resources (2012) Preliminary Report on the Northstar 1 Class II Injection Well and the Seismic Events in the Youngstown, Ohio Area (Ohio Department of Natural Resources, Columbus, OH). Available at http://ohiodnr.com/ downloads/northstar/UICreport.pdf. Accessed February 21, 2013.

16. Ellsworth W, et al. (2012) Are seismicity rate changes in the midcontinent natural or manmade? Seismol Res Lett 83(2):403.

17. Soeder D, Kappel W (2009) Water Resources and Natural Gas Production from the Marcellus Shale. U.S. Geological Survey Fact Sheet 2009-3032 (US Geological Survey، West Trenton, NJ). Available at http://pubs.usgs.gov/fs/2009/3032/pdf/FS2009-3032.pdf. Accessed February 21, 2013.

18. Pennsylvania State University, College of Agricultural Sciences (2010) Shaping Proposed Changes to Pennsylvania's Total Dissolved Solids Standard: A Guide to the Proposal and the Commenting Process (Pennsylvania State Univ, University Park, PA). Available at http://extension.psu.edu/water/conservation/consumption-and-usage/TDShighres-updateDec09.pdf/view. Accessed February 21, 2013.

19. Kaushal SS, et al. (2005) Increased salinization of fresh water in the northeastern United States. Proc Natl Acad Sci USA 102(38):13517-13520.

20. Nelson S, Yonge D, Barber M (2009) Effects of road salts on heavy metal mobility in two eastern Washington soils. J Environ Eng 135(7):505-510.

21. Novotny E, Stefan H (2010) Projections of chloride concentrations in urban lakes receiving road de-icing salt. Water Air Soil Pollut 211(1-4):261-271.

22. Williams H, Havens D, Banks K, Wachal D (2008) Field-based monitoring of sediment runoff from natural gas well sites in Denton County, Texas, USA. Environ Geol 55(7): 1463-1471.

23. US Environmental Protection Agency, Office of Research and Development and Office of Water (2006) Wadeable Stream Assessment: A Collaborative Survey of the Nation's Streams, EPA 841-B-06-002 (US Environmental Protection Agency, Washington, DC).

24. New York Department of Environmental Conservation (2011) Revised draft supplemental generic environmental impact statement on the oil, gas and solution mining regulatory program, well permit issuance for horizontal drilling and highvolume hydraulic fracturing to develop the Marcellus Shale and other lowpermeability gas reservoirs. Available at www.dec.ny.gov/docs/materials_minerals_pdf/ rdsgeisexecsum0911.pdf. Accessed February 21, 2013. 